\title{
Scientometric analysis of synchronous references in the Physics Nobel lectures, 1981-1985: A pilot study
}

\author{
RekHa P. Upadhye, V. L. Kalyane, Vijai Kumar, E. R. Prakasan \\ Bhabha Atomic Research Centre, Mumbai (India)
}

\begin{abstract}
Scientometric analysis of synchronous references in the nine Physics Nobel lectures by Nicolaas Bloembergen (1981), Arthur L. Schawlow (1981), Kai M. Siegbahn (1981), Kenneth G. Wilson (1982), Subrahmanyan Chandrasekhar (1983), William A. Fowler (1983), Carlo Rubbia (1984), Simon van der Meer (1984), and Klaus von Klitzing (1985) indicated high variations: No. of Synchronous References ranged from 24 (Meer) to 283 (Siegbahn); Synchronous Self-References ranged from 5 (Rubbia) to 88 (Siegbahn); synchronous references to others ranged from 10 (Chandrasekhar) to 255 (Wilson); Synchronous Self-Reference Rates ranged from 6.66 \% (Rubbia) to $65.51 \%$ (Chandrasekhar); Single-Authored References ranged from 15 (Klitzing) to 160 (Wilson); Multi-Authored References ranged from 4 (Chandrasekhar) to 194 (Siegbahn); Collaboration Coefficient in the synchronous references ranged from 0.14 (Chandrasekhar) to 0.75 (Klitzing); and Recency (age of $50 \%$ of the latest references) ranged from 2 (Klitzing) to 18 (Chandrasekhar) years. Seventy five per cent of the references belonged to journal articles. Highly referred journals were Astrophysical Journal, Physical Review B, Physical Review Letters, Arkiv Fuer Fysik, Surface Science, Physics Letters, and IEEE Transactions on Nuclear Science.
\end{abstract}

Keywords: Physics Nobel Lectures; Nicolaas Bloembergen; Arthur L. Schawlow; Kai M. Siegbahn; Kenneth G. Wilson; Subrahmanyan Chandrasekhar; William A. Fowler; Carlo Rubbia; Simon van der Meer; Klaus von Klitzing; Scientometrics; Synchronous References 


\section{Introduction}

Each year the media devotes considerable attention to winners of the Nobel Prize as it is prestigious for the nation to which they belong. Limitation of Nobel Prize is that it is given to only living scientists and can be shared by maximum three persons in each category: chemistry, physics, physiology or medicine, literature, economics, and for work towards world peace. Nobel Prize aims at motivating younger generation to seek career in science and technology. All efforts are made to project lifetime achievements of a Nobel laureate as hero of narrow field of specialization who has dedicated for revealing verifiable truth.

The analysis of publication productivity of Nobel laureates before and after getting the prize has been the subject of study by several workers. Institute for Scientific Information (ISI) publishes disciplinewise lists of most cited papers and most cited authors (GARFIELD \& WeLlJAMS-DOROF, 1992) to forecast Nobel Prize winners. GARFIELD \& MALIN (1968) ranked the most cited 50 scientists based on citation data of Science Citation Index, 1967. From this list already L. D. Landau, physics; L. Pauling, chemistry; J. C. Eccles, medicine; R. S. Mulliken, chemistry; F. Jacob, medicine had received the Nobel Prize (SEN et al., 1998). In 1969 itself two scientists (M. GellMann for physics and D. H. R. Barton for chemistry) from that list won the Nobel Prize. Several scientists (H. C. Brown, chemistry; G. Herzberg, chemistry; N. F. Mott, physics; C. Deduve, medicine; U. S. Von Euler, chemistry; and P. J. Flory, chemistry) from the list received the Nobel Prize afterwards. Sometimes predictions may go wrong for example for the year 2003 (ISI, 2003a).

MYERS (1970) showed that recipients of major awards and honors

typically have high citation counts. Peer evaluation for quality of 
work correlated highly with citations (CLARK, 1957). Nobel Prize winners, and members of the Royal Society, the National Academy of Sciences, and other highly regarded organizations tend to have high citations credits (GARFIELD, 1977).

Michael Nobel, the great-grand-nephew of Alfred Nobel during an interview at Bangalore (India) said (regarding Nobel prizes): "Yes, I believe one of the main reasons the prize is still considered the ultimate accolade, more than 100 years after its institution, is the recognition of the high quality of the selection process. There are some scientists and authors who people think have been left out and some laureates-very few-probably should not have received it. But of the many hundreds of choices, the overwhelming majority have been correct" (MANU RAO, 2001). Furthermore, the process of discovery may be so long that several scientists will succeed one another before it is completed, and besides the well recognized problem of collaborative research, and there is also the problem of simultaneous independent discoveries (LINDAHL, 1992). It is clear that the choices of the Nobel Committees are more complex than simply identifying highly cited or most-cited scientists. Generally, a Committee looks for an area of research to recognize, and then identifies the key persons responsible for the advance, even if the course of selection is determined by dossiers on 120 individual scientists nominated by their peers (ISI, 2003b).

Publication productivity analysis on life-time achievements of individual Nobel laureates: C. V. Raman (KADEMANI et al., 1994), P. G. de Gennes (Kalyane \& SEN, 1996), S. Chandrasekhar (KADEMANi et al., 1996a), Barbara Mc-Clintock (KALYANE \& Kademani, 1997), D. C. Hodgkin (Kademani et al., 1999), A. H. Zewail (KADEMANi et al., 2001, KADEMANI et al., 2002a), H. W. Kroto (KADEMANI et al., 2002b), Wolfgang Ketterle 
(KOGANURAMATH et al., 2003), and Leland H. Hartwell (ANGADI et al., 2004) and diachronous citation analysis (using Science Citation Index) on Albert Einstein (CAWKell \& GARFIELD, 1980), P. A. M. Dirac (KRAGH, 1990), and S. Chandrasekhar (GUPTA, 1983) for example are available.

MABE and AMIN (2002) delineated three phases of knowledge generation: sowing, nurturing and reaping by depicting a case study of Nobel Prizewinner 1996. In the first phase (sowing) papers appear in low impact journals. Later, as the most fertile phase is approached, the number of papers and the quality of the journals used increase to a peak where the Nobel Prize winning research was conducted and key papers appear in high impact factor journals. Without publishing in the lower impact factor journals, the scientist would have had no means of commencing his publishing career. This pattern is repeated throughout the history of science.

BRAUN et al. (2003) has discussed the ranked lists of awardees as science indicators of national merit in Mathematics. Quantitative researchers have studied elites, including: content analyses of elite speeches (SEIDER, 1974), elite networks for decision making (KNOKE, 1993), elite cross-sectional survey data panel study (MURRAY, 1992), and publication productivity of elite Indian scientists (KALYANE et al., 2001) used for standardizing linear reference curve, which is expected to be surpassed by a current scientist for performance par excellence.

\section{Present study of Nobel lectures}

When Nobel award is announced in September-October every year, it is expected from Nobel Prize winners to address their award worthy research through the special Nobel lectures in December. These lectures are reviews of their research for which they received the Nobel Prize. Indeed main target audience of scholarly 
communications (BORGMAN \& FURNER, 2002) is scholars only. Nobel lectures are the milestones for the advancements of frontiers of science and technology, hence, Nobel laureates elaborate significance of their research leading to the accolade. These are retrospective (as these refer to almost all relevant research back in time), and prospective (as these may provide guidelines for future research) documents. Researchers convey relevance of the knowledge that their work has uncovered, describe how they discovered it, including background of how the work fits into the particular field.

Authors of this article have not come across any work on "Nobel lectures" except only one study (SEN, 1969) searching for references to papers by Indian scientists in Nobel lectures, where he considered that one of the reliable way to measure the most competent response to a scientist's work would be the study of references in the Nobel lectures. It may be assumed that those whose works are referred in the Nobel lectures could be taken as the most scholarly members of the scientific community with significant knowledge generated by them.

Researchers interested in the History of Communications in Science are the targets of present study.

\section{Materials and methods}

Physics Nobel lectures (1981-1985) from the source "Nobel Lectures Including Presentation Speeches and Laureates' Biographies: Physics 1981-1990" (FRÄNGSMYR, 1993) were used for synchronous references analysis. The Nobel lectures under the study are listed in Table 1.

Bibliographic data (synchronous references at the end of each Nobel lecture) were analysed as per the following indicators:

- Normal count procedure: One full score credit is given for each occurrence (KALYANE \& VIDYASAGAR RAO, 1995). 
- Collaboration Coefficient: The ratio of the number of collaborative publications to the total number of publications in a bibliography (SUBRAMANYAM, 1983).

- Synchronous (LAWANI, 1982) self-references rate: The ratio in percentage of self-references by the author in an article to the total number of references in the same article. For selfreferences count, the name of the author in the citing paper was searched for its occurrence irrespective of his/her authorship position in each of the synchronous references.

- Recency: Number of years (age) for the 50 per cent of the latest references. Each synchronous reference year was taken into consideration to know how far the referred article antedated (backward in time) to the Nobel lecture year (TAGLIACOZZO, 1977).

Table 1. Physics Nobel laureates, titles of Nobel lectures (1981-1985) and dates

\begin{tabular}{|c|c|c|c|}
\hline Code & Nobel laureate & Title of the Nobel lecture & Date \\
\hline A & N. Bloembergen & Nonlinear Optics and Spectroscopy & 8 Dec. 1981 \\
\hline B & A.L. Schawlow & Spectroscopy in a New Light & 8 Dec. 1981 \\
\hline C & Kai M. Siegbahn & $\begin{array}{l}\text { Electron Spectroscopy for Atoms, Molecules } \\
\text { and Condensed Matter }\end{array}$ & 8 Dec. 1981 \\
\hline $\mathrm{D}$ & Kenneth G. Wilson & $\begin{array}{l}\text { The Renormalization Group and Critical } \\
\text { Phenomena }\end{array}$ & 8 Dec.1982 \\
\hline E & S. Chandrasekhar & On stars, their Evolution and their Stability & 8 Dec. 1983 \\
\hline $\mathrm{F}$ & William A. Fowler & $\begin{array}{l}\text { Experimental and Theoretical Nuclear } \\
\text { Astrophysics: The Quest for the Origin of the } \\
\text { Elements }\end{array}$ & 8 Dec. 1983 \\
\hline G & Carlo Rubbia & $\begin{array}{l}\text { Experimental Observation of the Intermediate } \\
\text { Vector Bosons } W^{+}, W^{-} \text {and } Z^{0}\end{array}$ & 8 Dec. 1984 \\
\hline $\mathrm{H}$ & Simon van der Meer & $\begin{array}{l}\text { Stochastic Cooling and the Accumulation of } \\
\text { Antiprotons }\end{array}$ & 8 Dec. 1984 \\
\hline I & Klaus von Klitzing & The Quantized Hall Effect & 9 Dec.1985 \\
\hline
\end{tabular}

\section{Results and Discussion}

\section{Historical aspect of references in the Nobel Prize winning research}

The citations in the list of references have the historical relevance of these references to the research (HARTER, 1992). Nobel lectures are reviews of the research work for which Nobel Prizes have been awarded. Therefore, the references cited by the Nobel laureates in their Nobel lectures were analyzed. Cumulative number of references 
per year, in all of the nine Nobel lectures, are depicted in Figure 1 for overall perception of the growth of relevant knowledge.

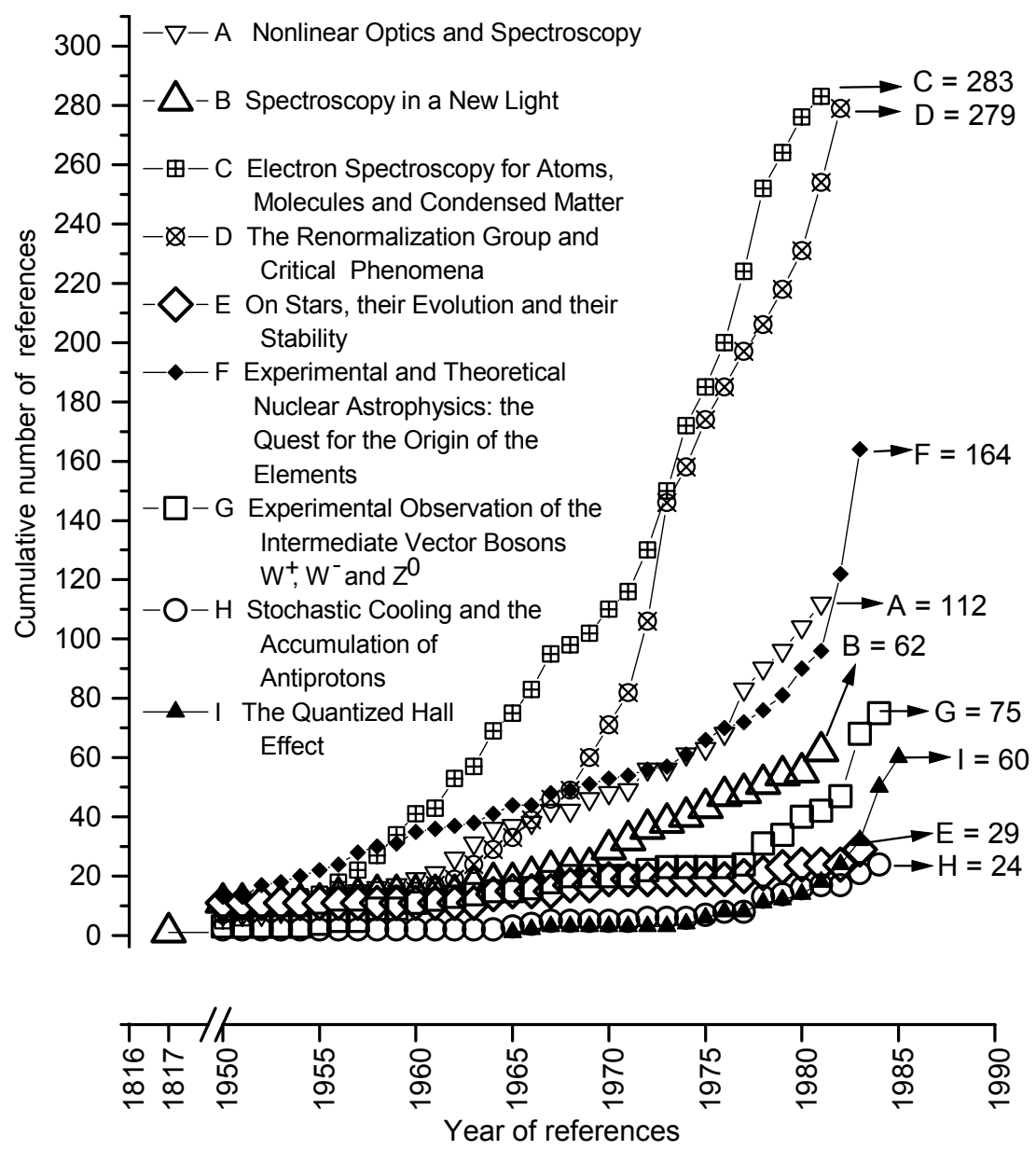

(Nobel lectures by : $A=$ Nicolaas Bloembergen, $B=$ Arthur L. Schawlow, $C=$ Kai $M$. Siegbahn, D = Kenneth G. Wilson, E = Subrahmanyan Chandrasekhar, F = William A. Fowler, $\mathrm{G}=$ Carlo Rubbia, $\mathrm{H}$ = Simon van der Meer, and I = Klaus von Klitzing)

Figure 1. Year-wise cumulative number of synchronous references in the Physics Nobel lectures (1981-1985)

A breakthrough in any field of research accelerates the activity in that field and a series of papers get published following the new ideas initiated and then reaches a saturation after a period of growth. The research opens new vistas, which are pursued by other global contemporaries also, verifying and using it for applications. Thus, 
they endorse its value (by citing it) through their publications that results into high productivity in the relevant field.

\section{Recency of references}

Figure 2 indicates number of years (age) for the 50 per cent of cited references preceding the citing Physics Nobel lectures (1981-85).

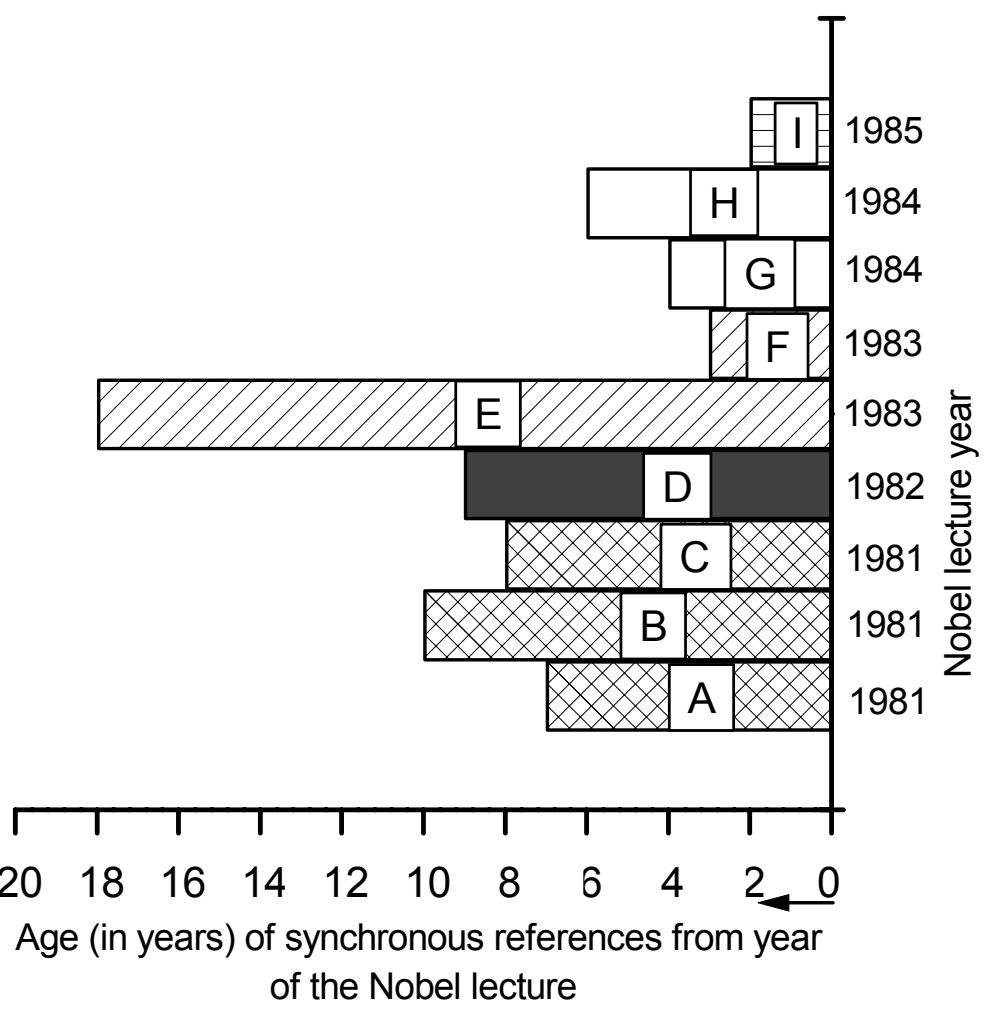

(Nobel lectures by: $A=$ Nicolaas Bloembergen, $B=$ Arthur L. Schawlow, $C=$ Kai $M$. Siegbahn, $D=$ Kenneth $G$. Wilson, $E=$ Subrahmanyan Chandrasekhar, $F=$ William $A$. Fowler, $\mathrm{G}=$ Carlo Rubbia, $\mathrm{H}$ = Simon van der Meer, and I = Klaus von Klitzing)

Figure 2 Recency (age for the 50 per cent of latest references) preceding the citing Physics Nobel lectures (1981-1985) where zero age is for the Nobel lecture year

For references in Nobel lecture by S. Chandrasekhar recency was 18 years. It was two years only for Nobel lecture by Klaus von Klitzing. The oldest reference (165 years old) referred in the Nobel lecture “Spectroscopy in a New Light" was of FRAUNHOFER (1817). DIEKS and SLOOTEN (1986) suggested that when an article can be regarded as a pioneering work in a certain discipline, the citation scores are determined more by the dynamics of the discipline than by the aging 
of the article. H. M. Tetrode's 1922 paper on "Quantum-mechanics" which was brought to the notice of J. A. Wheeler and R. P. Feynman by Albert Einstein after they had developed their own ideas on the time-symmetrical formalism of electrodynamics even now receives citations.

\section{Synchronous Self-references in Nobel lectures}

Table 2 shows self-references, references to others and synchronous self-reference rate in Physics Nobel lectures (1981-85).

\begin{tabular}{|c|c|c|c|}
\hline Code & $\begin{array}{l}\text { Self- } \\
\text { references }\end{array}$ & $\begin{array}{l}\text { References } \\
\text { to others }\end{array}$ & $\begin{array}{l}\text { Synchronous self- } \\
\text { reference rate }\end{array}$ \\
\hline A & 22 & 90 & 19.64 \\
\hline B & 21 & 41 & 33.87 \\
\hline C & 88 & 195 & 31.09 \\
\hline D & 24 & 255 & 8.60 \\
\hline$E$ & 19 & 10 & 65.51 \\
\hline $\mathrm{F}$ & 34 & 130 & 20.73 \\
\hline G & 5 & 70 & 6.66 \\
\hline $\mathrm{H}$ & 9 & 15 & 37.50 \\
\hline 1 & 12 & 48 & 20.00 \\
\hline Average & 26 & 94.89 & 27.07 \\
\hline Median & 21 & 70.00 & 20.73 \\
\hline \multicolumn{4}{|c|}{$\begin{array}{l}\text { (Nobel lectures by : A = Nicolaas Bloembergen, B = } \\
\text { Arthur L. Schawlow, C }=\text { Kai M. Siegbahn, D = } \\
\text { Kenneth G. Wilson, } \mathrm{E}=\text { Subrahmanyan } \\
\text { Chandrasekhar, } \mathrm{F}=\text { William A. Fowler, } \mathrm{G}=\text { Carlo } \\
\text { Rubbia, } \mathrm{H}=\text { Simon van der Meer, and I = Klaus von } \\
\text { Klitzing) }\end{array}$} \\
\hline
\end{tabular}

Out of nine Nobel laureates, Kai M. Siegbahn has referred to maximum (283) publications and Simon van der Meer has referred to minimum (24) number of publications.

It is seen that in case of self-references also Kai M. Siegbahn has maximum (88) number of self-references. Carlo Rubbia has only five self-references out of 75 total references. 
Citation (and publication) practices vary between fields and over time (MOED et al., 1985). GARFIELD (1979) had reported selfcitations for biochemistry (about 30 references per paper) and mathematics (less than 10 references per paper). The number of selfreferences (SNYDER \& BONZI, 1998) in the physical sciences is greater $(15 \%)$ than either the social sciences $(6 \%)$ or the humanities (6 \%). A case study of Physics in the Netherlands (1985-1994) by VAN LEEUWEN et al. (1996) and Dutch Chemistry (1980-1991) by MOED \& VAN DER VELDE (1993) found a self-reference rate of 29 per cent in each. Role of self-citations in the scientific production of Norway (1981-1996) has been discussed by AKSNES (2003).

Synchronous Self-Reference Rate (SSRR) varies from individual to individual as a unique behaviour of each individual. Same researcher may have changes in SSRR from time to time when shifts occur in working from one domain to other domain in the lifetime. SSRR may change as per the channel of communications preferred over a period of time. Synchronous Self-Reference Rate (SSRR) for S. Chandrasekhar (KADEMANI et al., 1996a) in various domains were: Plasma physics (20.4\%); Stochastic, statistical hydromagnetic problem in physics and astronomy (19.6\%); Mathematical theory of black holes and colliding waves (19.4\%); Stellar structure and stellar atmosphere (17.8\%); Radiative transfer and negative ion of hydrogen (14.9\%); Tensor-virial theorem (14.3\%); Relativistic astrophysics (12.6\%); and Hydromagnetic and hydrodynamic stability (10.5\%); SSRR for C. V. Raman (KADEMANI et al., 1994) in various domains were: Floral colours and visual perception (26.9\%); Physics of crystals (26.4\%); Optics (19.7\%); Optics of minerals and diamonds (19.6\%); Acoustics (11.7\%); and Scattering of light (5.6\%). SSRR for K. S. Krishnan (KADEMANI et al., 1996b) for various domains were: Thermionics (19.0\%); Magnetism (14.8\%); and Spectroscopy 
(9.8\%). SSRR for R. K. Mitra (KALYANE et al., 2001) calculated domain-wise were: Methodology (16.7\%); Biochemical genetics (14.8\%); Molecular biology (11.6\%); Bioenergetics (9.7\%); Plant biochemistry (4.2\%); and Biotechnology (0.0\%). Mean SSRR for C. R. Bhatia was 0.5 per cent (KALYANE \& SEN, 1998). Overall SSRR for following scientists were: Vikram Sarabhai - for Cosmic rays, 16.5\% (KADEMANI et al., 2000); R. Chidambaram - for highly cited and/or most significant publications, $12.2 \%$ (KADEMANI \& KALYANE, 1996); and R. G. Rastogi - for Geomagnetism, 25.1\% (MunNolli \& Kalyane, 2003). For the papers of Tibor Braun published in the core journals preferred by him to channelise his publications, SSRR was found to vary from 19 to 70 per cent (KALYANE \& SEN, 2003) as follows: Journal of Radioanalytical and Nuclear Chemistry Letters (70\%); Trends in Analytical Chemistry (30\%); Scientometrics (28\%); Analytica Chimica Acta (22\%); and Fresenius Zeitschrift fur Analytische Chemie, renamed as Fresenius Journal of Analytical Chemistry (19\%). In the case study of H. J. Bhabha first quinquennium and fifth quinquennium of his research career had low self-references; third quinquennium and fourth quinquennium had moderate self-references; whereas second quinquennium had highest self-references. The two major clusters of self-references occurring during the second and third quinquennium were indicators of active periods of knowledge-generating and faster communication (SWARNA et al., in press)

Synchronous self-reference rate for Nobel laureate Carlo Rubbia is $6.66 \%$, which is lowest among all nine Nobel laureates. Whereas highest synchronous self-reference rate is of S. Chandrasekhar (65.51\%). The self-references have a higher probability of referring to articles closely related to the work reported in the citing articles than 
other-author references. Figure 3 indicates percentage proportion of self-references and references to others.

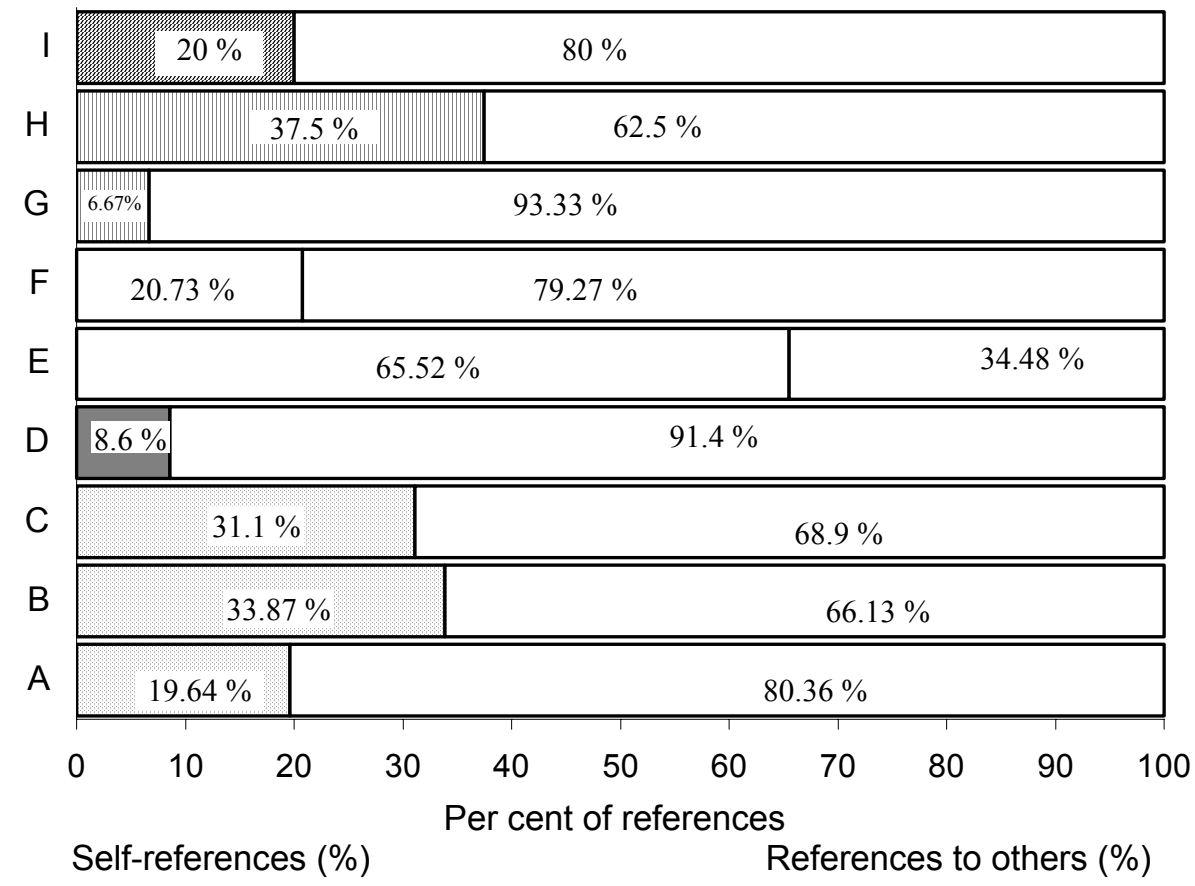

(Nobel lectures by : $A=$ Nicolaas Bloembergen, $B=$ Arthur L. Schawlow, $C=$ Kai M. Siegbahn, D = Kenneth G. Wilson, $E=$ Subrahmanyan Chandrasekhar, $F=$ William A. Fowler, $\mathrm{G}=$ Carlo Rubbia, $\mathrm{H}$ = Simon van der Meer, and I = Klaus von Klitzing)

Figure 3. Percentages of self-references and references to others observed in the references in the Physics Nobel lectures (1981-1985)

\section{Collaboration aspect in references cited}

Table 3 shows single-authored references, multi-authored references, and Collaboration Coefficient for synchronous references in Physics Nobel lectures (1981-85). It is seen that six Nobel laureates (N. Bloembergen, A. L. Shawlow, K. M. Siegbahn, W. A. Fowler, C. Rubbia and Klaus von Klitzing) out of the nine, have highly referred to multi-authored publications. Collaboration Coefficient in references for these six Nobel laureates lies between 0.61 (Carlo Rubbia) to 0.75 (Klaus von Klitzing). Nobel laureates S. Chandrasekhar, Simon van der Meer, and K. G. Wilson, have referred to single-authored references more than multi-authored references 
where Collaboration Coefficients are 0.14, 0.33, and 0.43 respectively. Figure 4 indicates the collaboration pattern (in percentages) observed in the sources referred to Physics Nobel lectures (1981-85).

Table 3: Single-authored, multi-authored references, and Collaboration Coefficient for synchronous references

in the Physics Nobel lectures (1981-85)

\begin{tabular}{cccc}
\hline Code & $\begin{array}{c}\text { Single-authored } \\
\text { references }\end{array}$ & $\begin{array}{c}\text { Multi- } \\
\text { authored } \\
\text { references }\end{array}$ & $\begin{array}{c}\text { Collaboration } \\
\text { Coefficient }\end{array}$ \\
\hline A & 33 & 79 & 0.71 \\
B & 17 & 45 & 0.73 \\
C & 89 & 194 & 0.69 \\
D & 160 & 119 & 0.43 \\
E & 25 & 4 & 0.14 \\
F & 58 & 106 & 0.65 \\
G & 29 & 46 & 0.61 \\
H & 16 & 8 & 0.33 \\
I & 15 & 45 & 0.75 \\
\hline Average & 49.11 & 71.77 & 0.56 \\
Median & 29 & 46 & 0.65 \\
\hline
\end{tabular}

(Nobel lectures by : $A=$ Nicolaas Bloembergen, $B=$ Arthur L. Schawlow, C = Kai M. Siegbahn, D = Kenneth G. Wilson, $E$ = Subrahmanyan Chandrasekhar, $F=$ William A. Fowler, $\mathrm{G}=$ Carlo Rubbia, $\mathrm{H}=\mathrm{Simon}$ van der Meer, and I = Klaus von Klitzing) 


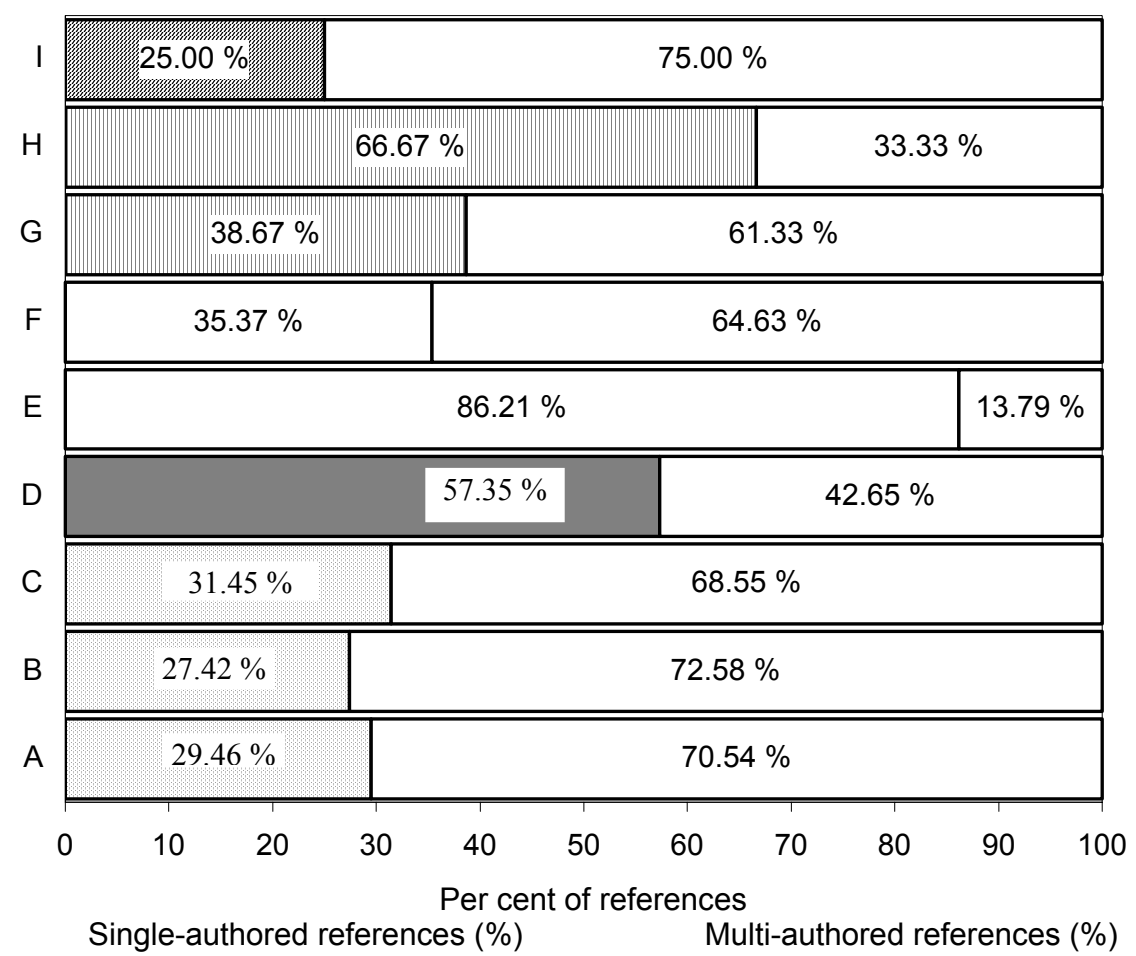

(Nobel lectures by : A = Nicolaas Bloembergen, B = Arthur L. Schawlow, C = Kai M. Siegbahn, $\mathrm{D}=$ Kenneth $\mathrm{G}$. Wilson, $\mathrm{E}=$ Subrahmanyan Chandrasekhar, $\mathrm{F}=$ William $\mathrm{A}$. Fowler, $\mathrm{G}=$ Carlo Rubbia, $\mathrm{H}=$ Simon van der Meer, and I = Klaus von Klitzing)

Figure 4. Collaboration pattern observed in the sources referred in the Physics Nobel lectures (1981-1985)

\section{Publication types}

Publication types referred in overall Physics Nobel lectures 1981-85 were: journals $(75.55 \%)$, books $(7.72 \%)$, series $(4.69 \%)$, theses $(4.14 \%)$, conference proceedings $(3.22 \%)$, reports $(2.48 \%)$, unpublished literature $(1.47 \%)$, private communication $(0.64 \%)$, and computer program $(0.09 \%)$.

\section{Highly referred journals}

Nobel lecture-wise highly referred journals with the frequency of references were as follows: N. Bloembergen as well as A. L. Schawlow had highly referred to the Physical Review Letters i.e. 20 
and 13 times respectively. Kai M. Siegbahn had referred to Arkiv Fuer Fysik, 28 times, and Kenneth G. Wilson had referred to Physical Review B, 43 times. S. Chandrasekhar and William A. Fowler had highly referred to the Astrophysical Journal i.e. 7 and 46 times respectively. Carlo Rubbia had referred to Physics Letters, 13 times and Simon van der Meer had referred to IEEE Transactions on Nuclear Science, three times, and Klaus von Klitzing had referred to Surface Science, 14 times.

\section{Conclusions}

Nobel lectures are excellent documents of scholarly communications. These can be a source for research in content analysis, and to understand the knowledge-generating-mechanism in a micro-theme of historical significance. Each Nobel lecture is a unique piece of content and style of presentation open for exploration. As James Clerk Maxwell said: "It is when we take some interest in the great discoverers and their lives that science becomes endurable, and only when we begin to trace the developments of ideas that it becomes fascinating." Through the analysis of synchronous references one can trace the origin and development of the ideas related to the topic of research. Variations in the development and growth pattern of the Nobel Prize-winning ideas have been visualized through the chronological analysis of synchronous references. Recency (i.e. age of the $50 \%$ of the latest synchronous references) indicates phase of faster growth in the knowledge and the knowledgeworkers dedicated to use it, when it is concentrated in the latest years. Single-authored references indicate efforts by an individual scientist to understand a phenomenon. Multi-authored references indicate collective efforts of the scientific community to solve the problem of interest to them at that point of time. Present study is a pilot quantitative documentation work, to attract attention of and motivate 
subject experts, with intentions to involve them in understanding the mechanism of origin of ideas, their development, demonstration, deployment, diffusion, and use, which leads to recognition of the micro-domain as well as may give birth to another new ideas. Publication of this idea will be justified if a few scholars at global level can devote some of their time to explore further possibilities.

\section{References}

AKSNES, D. W. (2003), A macro study of self-citation, Scientometrics, Vol.56 No.2, pp. 235-246.

Angadi, M., Koganuramath, M. M., Kademani, B. S., Kalyane, V. L., SEN, B. K. (2004), Scientometric portrait of Nobel laureate Leland H. Hartwell, Proceedings of International Workshop on Webometrics, Informetrics and Scientometrics, (2-5 March, 2004), Indian Institute of Technology, Roorkee, India, pp.10-30.

BORGMAN, C. L. and FURNER, J. (2002), Scholarly communication and bibliometrics, In: B. CRONIN (Ed.), Annual Review of Information Science and Technology, Information Today, Inc., New Jersey, 36, pp.3-72.

http://skipper.gseis.ucla.edu/faculty/jfurner/HTML/arist02.pdf

Braun, T., SzabAdi-PereszTegi, ZS. and KovÁCs-NÉmETH, É. (2003), About Abels and similar international awards for ranked lists of awardees as science indicators of national merit in mathematics, Scientometrics, Vol.56 No.2, pp. 161-168.

CAWKELL, T. and GARFIELD, E. (1980), Assessing Einstein's impact on today's science by citation analysis, In: GOLDSMITH, M., MaCKAy, A., WoudhuYsen, J., (Eds.), Einstein: The First Hundred Years, Pergamon, Oxford, pp.31-40.

ClARK, K. E. (1957), America's Psychologists: A Survey of a Growing Profession, American Psychological Association, Washington, D.C.

DieKS, D. and Slooten, W. J. (1986), Historic papers in Physics the case of Hugo Martin Tetrode, 1895-1931, Czechoslovak Journal of Physics, Vol.B36 No.1, pp.39- 42.

FRÄNGSMYR, T. (Ed.) (1993), Nobel Lectures Including Presentation, Speeches and Laureates' Biographies: Physics 1981-1990, World Scientific, Singapore, pp.1-346.

FRAUNHOFER, J. (1817), Bestimmung des Brechungs- und Farbenzerstreuungs- Vermoegens verschiedener Glasarten, in Bezug auf die Vervollkommnung achromatischer Fernroehre. Denkschriften der koeniglichen Akademie der Wissenschaften zu 
Muenchen, Vol.5, pp. 193-226 (also in: Gilberts Annalen der Physik, Vol.56, pp. 264-313).

GARFIELD, E. (1977), The 250 most-cited primary authors, 19611975. Part II. The correlation between citedness, Nobel Prizes and academy memberships, Current Contents, 12 Dec. [Reprinted in GARFIELD, E. (1980), Essays of an Information Scientist, Vol.3. 1977-1978, pp. 337-347, ISI Press, Philadelphia, P.A. http://www.isinet.com/isi/hot/essays/useofcitationdatabases/5.html

GARFIELD, E. (1979), Is citation analysis a legitimate evaluation tool?, Scientometrics, Vol.1 No.4, pp.359-75.

GARFIELD, E. and MALIN, M. V. (1968), Can Nobel Prize winners be predicted?, $135^{\text {th }}$ Annual Meeting, American Association for the Advancement of Science, Dallas, TX.

GARFIELD, E. and WellJAMS-DOROF, A. (1992), Of Nobel class: A citation perspective on high impact research authors, Theoretical Medicine, Vol.13 No.2, pp.117-135.

GUPTA, D. K. (1983), Chandrasekhar: Winner of the 1983 Nobel prize for Physics: A citation analysis study of his works, Annals of Library Science and Documentation, Vol.30 No.3-4, pp.177-184.

HARTER, S. P. (1992), Psychological relevance and information science, Journal of the American Society for Information Science, Vol.43 No.9, pp.602-615.

ISI (2003a), ISI (Institute for Scientific Information) Leading information solutions provider predicts Nobel Laureates, http://www.isinet.com/isi/news/2003/isi/8196745.

ISI (2003b), ISI (Institute for Scientific Information) - a Thomson business, Announces Citation Laureates...and its "Picks" as Possible Nobel Prizewinners in 2003 or after, http://in-cites.com/nobel/2003-nobel.html.

Kademani, B. S., KaLYANE, V. L. (1996), Outstandingly cited and most significant publications of R. Chidambaram, a nuclear physicist, Malaysian Journal of Library and Information Science, Vol.1 No.1, pp.21-36.

Kademani, B. S., Kalyane, V. L., Jange, S. (1999), Scientometric portrait of Nobel laureate Dorothy Crowfoot Hodgkin, Scientometrics, Vol.45 No.2, pp. 233-250.

Kademani, B. S., Kalyane, V. L., Kademani, A. B.(1994), Scientometric portrait of Nobel laureate Dr. C. V. Raman, Indian Journal of Information, Library and Society, Vol.7 No.3-4, pp.215-249.

Kademani, B. S., Kalyane, V. L., Kademani, A. B. (1996a), Scientometric portrait of Nobel laureate S. Chandrasekhar, JISSI: The International Journal of Scientometrics and Informetrics, Vol.2 No.2-3, pp. 119-135. 
Kademani, B. S., Kalyane, V. L., Kademani, A. B. (1996b), Scientometric portrait of Sir K. S. Krishnan. Indian Journal of Information, Library and Society, Vol.9, No.1-2, pp.125-150.

Kademani, B. S., Kalyane, V. L., ViJai Kumar. (2000), Scientometric portrait of Vikram Ambalal Sarabhai: A citation analysis, SRELS Journal of Information Management, Vol.37, No.2, pp.107-132.

Kademani, B. S., Kalyane, V. L., ViJai Kumar (2001), Scientometric portrait of Nobel laureate Ahmed Hassan Zewail, Malaysian Journal of Library and Information Science, Vol.6 No.2, pp.53-70.

Kademani, B. S., Kalyane, V. L., Vijai Kumar (2002a), A. H. Zewail: Research collaborator par excellence, Scientometrics, Vol.53 No.1, pp.113-121.

Kademani, B. S., Kalyane, V. L., ViJai Kumar (2002b), Scientometric portrait of Nobel laureate Harold W. Kroto, SRELS Journal of Information Management, Vol.39 No.4, pp.409-434.

KALYANE, V. L. and KADEMANI, B. S. (1997), Scientometric portrait of Barbara McClintock: The Nobel laureate in physiology, Kelpro Bulletin, Vol.1 No.1, pp. 3-14.

KALYANE, V. L. and SEN, B. K. (1996), Scientometric portrait of Nobel laureate Pierre-Gilles de Gennes, Malaysian Journal of Library and Information Science, Vol.1 No.2, pp.13-26.

KALYANE, V. L., SEN, B. K. (1998), Scientometric portrait of C. R. Bhatia - An Indian geneticist and plant breeder, Malaysian Journal of Library and Information Science, Vol.3, No.1, pp.2542.

Kalyane, V. L., Sen, B. K. (2003), Research productivity of Tibor Braun: An analytical chemist-cum-scientometrician, Annals of Library and Information Studies, Vol.50, No.2, pp.47-61.

KALYANE, V .L. and VIDYASAGAR RAO, K. (1995), Quantification of credit for authorship, ILA Bulletin, Vol.30 No.3-4, pp.94-96.

KALYANE V. L., MADAN V. K. and ViJAI KumAR (2001), Reference Curve for Indian Role Model Scientist, Malaysian Journal of Library and Information Science, Vol.6, No. 1, pp. 57-70.

Kalyane, V. L., Prakasan, E. R., ViJAI Kumar (2001), Scientometric portrait of Ranjit Kumar Mitra, ILA Bulletin, Vol.37, No.2, pp.39-53.

Koganuramath, M. M., Angadi, M., Kademani, B. S., KALYANE, V. L., JANGE, S. (2003), Scientometric portrait of Nobel laureate Wolfgang Ketterle, Knowledge Management in Special Libraries in Digital Environment, XXIV All India Conference of IASLIC and Special Interest Group (SIG) Meetings, Indian Association of Special Libraries Information Centres, Kolkata, Special Publication No. 43, Abstract pp.447. 
KNOKE, DAVID (1993), Networks of elite structure and decision making. Sociological Methods and Research, Vol.22 No.1, pp. 23-45.

Kragh, H. (1990), Dirac bibliometrics, In: Dirac : A Scientific Biography, Cambridge University, Cambridge, pp.293-303.

LAWANI, S. M. (1982), On the heterogeneity and classification of author self-citations, Journal of the American Society for Information Science, Vol.33 No.5, pp.281-284.

LINDAHL, B. I. B. (1992), Discovery, theory change, the Nobel prize: On the mechanisms of scientific evolution, An introduction, Theoretical Medicine, Vol.13 No.2, pp.97-116.

MABE, M. A. and AMIN, M. (2002), Dr. Jekyll and Dr. Hyde : Author-reader asymmetries in scholarly publishing, Aslib Proceedings, Vol.54 No.3, pp.149-157.

MANU RAO, B. S. (2001), Nobel thoughts, The Times of India, Vol. CLXIV No. 264, Tuesday, November 6, 2001, p.10.

MoED, H. F., Burger, W. J. M., FrAnKFORT, J. G. and VAN RAAN, A. F. J. (1985), The application of bibliometric indicators: important field-and time-dependent factors to be considered, Scientometrics, Vol.8 No.3-4, pp. 177-203.

MOED, H. F. and VAN DER VELDE, J. G. M. (1993), Bibliometric profiles of academic chemistry research in the Netherlands, Centre for Science and Technology Studies, Report CWTS-93-08, Leiden.

MunNolli, S. S., Kalyane, V. L. (2003), Scientometric portrait of Ram Gopal Rastogi, Annals of Library and Information Studies, Vol.50, No.1, pp.1-17.

MURRAY, SHOON (1992), Turning an elite cross-sectional survey into a panel study while protecting anonymity, Journal of Conflict Resolution, Vol.36 No.3, pp.586-595.

MYERS, C. R. (1970), Journal citations and scientific eminence in contemporary psychology, American Psychologist, Vol.25, No.11, pp. 1041-1048.

SEIDER, M. S. (1974), American big business ideology: A content analysis of executive speeches, American Sociological Review, Vol.39 No.6, pp. 802-815.

SEN, B. K. (1969), Indian contributions to Nobel lectures, Annals of Library Science and Documentation, Vol.16 No.1, pp.35-36.

SEN, B. K., PANDAlai, T. A., KARANJAi, ARUNA (1998), Ranking of scientists - A new approach, Journal of Documentation, Vol.54 No.5, pp.622-628.

SNYDER, H. and BONZI, S. (1998), Patterns of self-citations across discipline (1980-1989), Journal of Information Science, Vol.24 No.6, pp.431-435. 
SUBRAMANYAM, K. (1983), Bibliometric studies of research collaboration: A review, Journal of Information Science, Vol.6 No.1, pp.33-38.

Swarna, T., Kalyane, V. L., Prakasan, E. R., Vijai Kumar (in press), Classic-Author Synchronous Self-References: The knowledge-generating-system at an individual scientist level.

TAGLiaCOZZO, R. (1977), Self-citations in scientific literature, The Journal of Documentation, Vol.33 No.4, pp.251-265.

VAN LeEUwen, T. N., Rinia E. J., VAN RAAN, A. F. J. (1996), Bibliometric profiles of academic physics research in the Netherlands, Centre for Science and Technology Studies, Report CWTS 96-09, Leiden. 